
\title{
$\angle S$ Research Square \\ Effect of artificial tears on aqueous deficient dry eye, a dynamic optical study
}

\section{Zhenyu Wei}

Beijing Institute of Ophthalmology https://orcid.org/0000-0001-5072-1883

\section{Yuandong Su}

Beijing Tongren Hospital

\section{Guanyu Su}

Beijing Tongren Hospital

\section{Christophe Baudouin}

Quinze-Vingts National Ophthalmology Hospital

\section{Antoine Labbé}

INSERM

Qingfeng Liang ( $\square$ lqflucky@163.com )

Beijing Institute of Ophthalmology https://orcid.org/0000-0003-0000-3167

\section{Research article}

Keywords: Objective scatter index, Tear film, Artificial tear, aqueous deficient dry eye

Posted Date: April 20th, 2020

DOl: https://doi.org/10.21203/rs.3.rs-21773/v1

License: (c) (1) This work is licensed under a Creative Commons Attribution 4.0 International License. Read Full License 


\section{Abstract}

Background: To investigate the change of dynamic optical quality in aqueous deficient dry eye (ADDE) patients after the use of artificial tears.

Methods: Fifty-nine patients with ADDE and 31 healthy age- and sex-matched control subjects were included in this prospective case-control study. Clinical evaluation of the ocular surface included Ocular Surface Disease Index (OSDI), tear film break-up time (TBUT), lipid layer thickness (LLT), and Schirmer I testing. ADDE patients were divided into two groups, mild (31 patients) and severe (28 patients). The optical quality of the tear film was measured with the Optical Quality Analysis System (OQAS) using the mean objective scatter index (mean OSI), standard deviation of objective scatter index (SD-OSI) and modulation transfer function cut-off (MTF cut-off). After baseline examinations, one drop of artificial tears (ATs, carboxymethylcellulose ophthalmic solution, $0.5 \%$ ) was instilled in both eyes, and optical quality parameters were measured again at 5- and 30-minutes following application of ATs.

Results: At baseline, the mean OSI was higher in the ADDE group $(0.95 \pm 0.54)$ than in controls $(0.54 \pm$ $0.23, P<0.001)$. The SD-OSI was also significantly increased in ADDE patients $(0.44 \pm 0.71)$ compared to control subjects $(0.12 \pm 0.06, P=0.003)$. Five minutes after ATs instillation, mean OSI and SD-OSI decreased significantly in severe ADDE patients $(P=0.044 ; P=0.018)$, was unchanged in mild ADDE patients, and increased in the control group $(P=0.019 ; P<0.001)$. Thirty minutes after ATs instillation, no significant difference in optical quality parameters was observed for the three groups.

Conclusion: The effect of ATs on optical quality in patients with ADDE may differ according to the severity of the disease. Measurement of optical quality might be a promising tool to evaluate the effects of various ATs and possibly individualize treatment in ADDE patients.

\section{Background}

Dry eye disease (DED) is a multifactorial disease of the ocular surface characterized by an unstable tear film associated with symptoms of ocular surface irritation and visual impairment ${ }^{[1]}$. In addition to its nutritive and mechanical roles on the ocular surface, the tear film can mask irregularities of the corneal epithelium, and consequently, it is a central component of the refractive system of the eye. Break-up of the precorneal tear film can cause irregular astigmatism in excess of 1 diopter ${ }^{[2]}$. In clinical practice, fluctuating vision or decreased visual quality is a common complaint in DED patients. Several studies ${ }^{[3-8]}$ have shown increased higher-order aberrations ( $\mathrm{HOA}$ ) and objective scatter index (OSI) in DED patients. A previous study by our group also demonstrated that OSI fluctuations were significantly increased in eyes with DED, and the degree of fluctuations was correlated with the severity of DED ${ }^{[4]}$. Habay et al. showed similar results, with both the mean value and standard deviation of the OSI significantly decreased in severe dry eye patients ${ }^{[9]}$. 
Artificial tears (ATs), as standard, first-line therapy, are usually used in DED patients, especially in aqueous deficient dry eye (ADDE) patients. Water-retentive polymers such as carboxymethylcellulose (CMC) have always been incorporated in ATs formulations to supplement the aqueous, maintain/restore the stability of the tear film, and protect the ocular surface ${ }^{[10]}$. Although ATs decrease ocular surface symptoms in DED patients, some patients complain of transient blurry vision or decreased visual acuity after ATs use. Consequently, several studies evaluating optical quality after instilling artificial tear drops have been performed, but the results have been controversial. Some studies ${ }^{[11]}$ have reported that visual quality, as reflected by high order aberrations ( $\mathrm{HOA}$ ), deteriorates after instilling artificial tear drops, while some studies have revealed that visual quality improves and is sustained for some time after instillation ${ }^{[12]}$. Several reasons might explain these conflicting results, including non-objective methods of evaluation or differing severities of ADDE. Consequently, in the present study, we used the double pass Optical Quality Analysis System (OQAS), to evaluate the visual quality of ADDE patients with differing severities after the use of $0.5 \%$ CMC ATs. The goal was to evaluate the effect of ATs on optical quality in ADDE patients.

\section{Methods}

\section{Subjects}

This study was conducted at the Beijing Tongren Hospital with the approval of the hospital's Medical Ethics Committee (TREC-2017-KY021). All subjects were informed of the goals of the study, and their consent was obtained in accordance with the declaration of Helsinki. A total of 59 ADDE patients (36 women and 23 men; mean age $36.05 \pm 12.56$ years; range $18-72$ years) were consecutively recruited from July 2018 to August 2019. According to the consensus report by the International Dry Eye Workshop (2007) ${ }^{[13]}$, the inclusion criteria for the ADDE group were as follows: (1) age > 18 years; (2) Ocular Surface Disease Index (OSDI) score greater than 12; (3) tear film break-up time (TBUT) less than 10 seconds; (4) Schirmer I test at 5 minutes less than $10 \mathrm{~mm}$. According to the severity-grading scheme of the 2007 Workshop [13], ADDE patients were divided into two groups (mild and severe). The severe ADDE group (28 patients) was including these patients with Schirmer I test $\leq 5 \mathrm{~mm}$. The mild ADDE group (31 patients) consisted of patients with Schirmer I test between 5 and $10 \mathrm{~mm}$. Thirty-one age- and gendermatched control subjects (21 women and 10 men; mean age $38.13 \pm 13.79$ years, range 18-67 years) were also recruited with Schirmer I test result exceeding $10 \mathrm{~mm}$ at 5 minutes, TBUT above 10 seconds and an OSDI score below 13. The exclusion criteria for both groups were as follows: (1) age < 18 years; (2) subjects unable to complete the questionnaire or understand the procedures; (3) best corrected visual acuity less than 20/20; (4) presence of ocular or systemic disease or the use of topical or systemic medications that may affect the ocular surface, and (5) previous history of eye surgery or contact lens wear.

\section{Clinical Evaluation}

Each subject underwent a quantification of ocular surface symptoms with the Ocular Surface Disease Index (OSDI) questionnaire (range $0-100)^{[14]}$. Optical quality and ocular surface examinations were then 
performed in the following order: double-pass optical quality analysis, lipid layer thickness measurement (LLT), TBUT and Schirmer I testing.

The lipid layer thickness was measured with the Lipiview II® device (Tear science, Morrisville, NC, USA). The interferometric color unit (ICU) value reflected the local LLT with 1 ICU equivalent to $1 \mathrm{~nm}$ of lipid layer thickness. TBUT was measured using sterile fluorescein strips impregnated with $0.6 \mathrm{mg}$ fluorescein sodium (Alcon Laboratories, St. Louis, MO, USA). After applying $50 \mu \mathrm{L}$ of normal saline solution to the paper strip, it was touched to the inferior fornix. The interval between a complete blink and the appearance of the first dry spot was noted. TBUT was measured 3 times and the average calculated. The Schirmer test was performed without anesthesia, after having the patient's eyes closed for 5 minutes.

\section{Objective scatter index measurement}

The Optical Quality Analysis System (OQAS-II, Visiometrics, Tarrasa, Spain), was used to evaluate aberrations and intraocular scatter with the 2 following parameters: objective scatter index (OSI) and modular transfer function cut-off (MTF cut-off). The OSI is defined as the ratio between the integrated light in the peripheral ring and the central peak of the double-pass (DP) image. It represents the impact of aberration and scattering on the DP image. The MTF cut-off reflects the highest spatial frequencies that can be distinguished by patients' eyes. The subjects were tested with their best correction and instructed to blink freely during the double-pass analysis. The "Tear Film Analysis" program of the commercially available OQAS device was used to record dynamic changes in OSI values. This program consisted of a 20-second examination with OSI measurement every $0.5 \mathrm{sec}$, providing a graph showing the change in OSI over time. The pupil size was set at $7 \mathrm{~mm}$ to cover the majority of the tear film. After measurement, the mean value and standard deviation of the 20 -second OSI was available and recorded as "mean OSI" and "SD OSI," respectively.

After baseline examination, one drop of artificial tears (carboxymethylcellulose ophthalmic solution $0.5 \%$, Refresh Plus, Allergan Pharmaceuticals, Ireland) was instilled in both eyes. Five and 30 minutes after application, the OQAS examinations were performed again in all subjects. The difference between the mean $\mathrm{OSI}$ at baseline and at 5 and 30 minutes $\left(\mathrm{OSI}_{5 \mathrm{~min}}, \mathrm{OSI}_{30 \mathrm{~min}}\right)$ were analyzed, and the relationship between OSI and DED severity was evaluated.

\section{Statistical analysis}

Statistical analysis was performed with SPSS for Windows, version 22.0 (SPSS Inc., Chicago, IL, USA). For each subject, both eyes were tested, and the right eye was selected for analysis. All values were expressed as mean \pm SD. The normality of the data was analyzed using the Shapiro-Wilk test. The normal data were compared before and after treatment with the paired t-test, and the non-normal data were used for the paired rank-sum test. A Bonferroni correction of multiple comparisons was included. The generalized estimation equation was used to compare the repeated measurement data at each time point and within each treatment group. The Spearman correlation test was used to evaluate the 
correlation betweenthe visual quality parameters and dry eye clinical tests. A P $<0.05$ was considered statistically significant.

\section{Results}

\section{Subject clinical characteristics}

There was no difference with respect to gender $(P=0.342)$ or age $(P=0.847)$ between the ADDE (mild and severe group) and control groups. With regard to ocular surface symptoms, ADDE patients had more symptoms (OSDI score: mild group $24.04 \pm 5.22$, severe group $52.66 \pm 14.10)$ than normal controls (8.67 $\pm 3.29)$ (all $P<0.001)$. In addition, the TBUT in the mild $(4.05 \pm 1.08 \mathrm{sec})$ and severe $(3.17 \pm 0.99 \mathrm{sec})$ ADDE groups was significantly shorter than in normal controls (11.84 $\pm 3.12 \mathrm{sec}),(P<0.001)$. Compared to control subjects $(16.26 \pm 4.98 \mathrm{~mm})$, the Schirmer I test was lower in the mild $(8.48 \pm 2.74 \mathrm{~mm}, P<0.001)$ and severe group $(3.83 \pm 1.25 \mathrm{~mm} ; P<0.001)$. The mild and severe ADDE patients had significantly lower LLT $(59.29 \pm 15.53 \mathrm{~nm}, \mathrm{P}=0.015 ; 54.14 \pm 16.84 \mathrm{~nm}, \mathrm{P}=0.001)$ compared to normal controls $(70.81 \pm 19.33$ $\mathrm{nm})$. However, no statistical difference in LLT was observed between two ADDE groups $(P=0.223)$ (Table 1).

\section{Optical quality analysis at baseline}

The results of the optical quality examinations at baseline showed that the MTF cut-off value in the mild (32.11 $\pm 11.16, \mathrm{P}=0.002)$ and severe $(32.84 \pm 11.84, \mathrm{P}=0.004)$ groups was significantly decreased, compared to normal subjects $(40.96 \pm 9.07)$. The mean OSI was significantly increased in the severe group $(1.05 \pm 0.65, P<0.001)$ compared with normal subjects $(0.54 \pm 0.23)$. This difference was not significant in the mild group $(0.83 \pm 0.38, P=0.020)$. There was no statistical difference between the mild and severe ADDE groups for the mean OSI $(P=0.060)$. The value of SD OSI in severe ADDE group $(0.47 \pm$ $0.72)$ was significantly higher than in normal subjects $(0.12 \pm 0.06)(P=0.004)$ and there was no significant difference between the mild $(0.41 \pm 0.69)$ and the control group $(P=0.024)$ (Figure 1). There were a significant difference between MTF cut-off, mean OSI and SD OSI, within ADDE patients and control subjects $(P=0.012, P<0.001, P=0.003)$.

\section{Changes in optical quality after ATs application}

Five minutes after ATs instillation, the mean and SD of the OSI increased significantly in the control group, from $0.54 \pm 0.23$ and $0.12 \pm 0.06$ at baseline to $0.69 \pm 0.27$ and $0.20 \pm 0.10$, respectively $(P=0.019$ and $\mathrm{P}<0.001)$. In the mild group, the mean OSI $(1.00 \pm 0.48)$ and the SD OSI $(0.13 \pm 0.05)$ did not change significantly compared to the baseline results $(0.83 \pm 0.38, P=0.155 ; 0.40 \pm 0.70, P=0.066)$. In the severe group, both the mean OSI ( $0.78 \pm 0.36$ vs. $1.05 \pm 0.65, P=0.044)$ and the SD OSI $(0.15 \pm 0.08$ vs. $0.47 \pm$ $0.72, \mathrm{P}=0.018)$ decreased significantly at 5 minutes after ATs application. Inversely, compared to baseline values, the parameters of mean and SD OSI had no significant difference at 30 minutes after ATs instillation in all groups (Table 2). 


\section{Correlation between change in optical quality and clinical tests}

Within the DED groups, there were significant negative correlations between TBUT and mean OSI $(r=$ $-0.329, P=0.011)$, and TBUT and SD-OSI $(r=-0.330, P=0.011)$. TBUT was also positively correlated with

the $\Delta O_{S S} I_{5 \min }(r=0.261, P=0.045)$. Similarly to the TBUT, the Schirmer I test was negatively correlated with the mean OSI $(r=-0.251, P=0.050)$ and SD-OSI $(r=-0.349, P=0.007)$, and positively correlated with the $\Delta \mathrm{OSI}_{5 \min }(r=0.457, \mathrm{P}=0.000)($ Table 3$)$.

\section{Discussion}

When considering the effects of ATs on DED patients, the results of preavious studies evaluating the quality of vision have been controversial ${ }^{[18-24]}$. In 1993, Rieger et al. ${ }^{[22]}$ suggested that the ATs could improve contrast sensitivity for severe DED patients. Misaki et al. ${ }^{[23]}$ detected the variation of visual acuity after different concentrations of ATs and found that no significant difference within mild patients' visual acuity after 5 minutes of ATs application. However, these two studies have only focused on the changes in visual quality few minutes after ATs instillation. Tung et al. ${ }^{[24]}$ had different results with a decrease in visual quality 5 minutes after ATs instillation but they did not analyze different DED severity groups. In the present study, 5 minutes after instillation, the severe and mild dry eye and normal subjects showed differing results. An increase in optical quality was observed in the severe group, there was no change in the mild group, and significant degradation of optical quality was shown in normal subjects. The improvement in optical quality may be related to the severity of tear volume deficiency. In the severe group, in whom the Schirmer I test was less than $5 \mathrm{~mm}$, artificial tears can quickly restore the aqueous layer and the optical role of the tear film on the ocular surface. In the mild group, a trend toward improvement in the SD OSI was observed, but these changes were not significant.

\section{Conclusions}

In summary, our data indicate that optical quality will be improved significantly after five minutes ATs instillation in severe ADDE cases and unchanged in mild ADDE cases, decreased in the normal controls. For this reason, measurement of optical quality could be a promising tool to evaluate the effects of ATs in ADDE patients. The data support our hypothesis that the visual quality of ADDE patients will be influenced by the ATs application and these differences will depend on the severity of ADDE. To make up for the lack of present research, our future studies would focus on effect of the various ATs and the dynamic changes of optical quality. We would also internalize these patients with evaporative dry eye.

Our present and future studies could eventually help ADDE patients to acquire an individual therapy in ATs selection. This also has a profound significance to improve the component and technology of artificial tears.

\section{Abbreviations}


ADDE: Aqueous Deficient Dry Eye; ATs: Artificial tears; DED: Dry eye disease; DP: Double-pass; HOA: Higher-order aberrations; ICU: Interferometric color unit; LLT: Lipid layer thickness; Mean OSI: Mean Objective Scatter Index; MTF cut-off: Modulation transfer function cut-off; OSDI: Ocular Surface Disease Index; OSI: Objective scatter index; OQAS: Optical Quality Analysis System; SD-OSI: Standard deviation of objective scatter index;TBUT: Tear film break-up time

\section{Declarations}

\section{Ethics and consent to participate}

This study was conducted at the Beijing Tongren Hospital with the approval of the hospital's Medical Ethics Committee (TREC-2017-KY021). All subjects were informed of the goals of the study. In accordance with Helsinki declaration, written and verbal consent for participation in the study was obtained from all participants.

\section{Consent for publication}

Not applicable.

\section{Availability of data and materials}

The datasets used and analyzed in this study are available from the corresponding author on reasonable request.

\section{Competing interests}

The authors declare that they have no competing interests.

\section{Funding}

National Nature Science Foundation of China (81970765); Beijing Science and technology project (Z181100001918031), China.

\section{Authors' contribution}

Zhenyu Wei and Yuandong Su analyzed and interpreted the data and were the major contributors in writing the manuscript. They contributed equally to this work. Qingfeng Liang, as the corresponding author, was primarily responsible for experimental design and paper revision. Guanyu Su and leying Wang had the contribution to data acquisition and the work draft. Christophe Baudouin and Antoine Labbé made a substantial contribution to the revision of the manuscript.

\section{Acknowledgements}

We gratefully acknowledge the research participants who contributed samples for this study. 


\section{References}

1. Tsubota K, Yokoi N, Shimazaki J, et al. New Perspectives on Dry Eye Definition and Diagnosis: A Consensus Report by the Asia Dry Eye Society. Ocul Surf 2017, 15(1):65-76.

2. Montes-Mico R. Role of the tear film in the optical quality of the human eye. Journal of cataract and refractive surgery 2007, 33(9):1631-1635.

3. Kobashi H, Kamiya K, Yanome K, et al. Longitudinal assessment of optical quality and intraocular scattering using the double-pass instrument in normal eyes and eyes with short tear breakup time. PloS one 2013, 8(12):e82427.

4. Tan $\mathrm{CH}$, Labbe A, Liang Q, et al. Dynamic change of optical quality in patients with dry eye disease. Invest Ophthalmol Vis Sci 2015, 56(5):2848-2854.

5. Yan Jiangbo, et al. A double-pass method of evaluating the optical quality of dry eye caused by meibomian gland dysfunction. Chinese Journal of Optometry Ophthalmology and Visual science. 2015, 11(17).

6. Montes-Mico R, Alio JL, Munoz G, et al. Temporal changes in optical quality of air-tear film interface at anterior cornea after blink. Invest Ophthalmol Vis Sci 2004, 45(6):1752-1757.

7. Li KY, Yoon G. Changes in aberrations and retinal image quality due to tear film dynamics. Optics express 2006, 14(25):12552-12559.

8. Montes-Mico R, Alio JL, Charman WN. Dynamic changes in the tear film in dry eyes. Invest Ophthalmol Vis Sci 2005, 46(5):1615-1619.

9. Habay T, Majzoub S, Perrault O, et al. Objective assessment of the functional impact of dry eye severity on the quality of vision by double-pass aberrometry. J Fr Ophtalmo/ 2014, 37(3):188-194.

10. Albarran C, Pons AM, Lorente A, et al. Influence of the tear film on optical quality of the eye. Cont Lens Anterior Eye 1997, 20(4):129-135.

11. Goto E, Yagi Y, Matsumoto Y, et al. Impaired functional visual acuity of dry eye patients. Am J Ophthalmol 2002, 133(2):181-186.

12. Montes-Mico R, Caliz A, Alio JL. Wavefront analysis of higher order aberrations in dry eye patients. Journal of refractive surgery (Thorofare, NJ : 1995) 2004, 20(3):243-247.

13. The definition and classification of dry eye disease: report of the Definition and Classification Subcommittee of the International Dry Eye WorkShop (2007). Ocul Surf 2007, 5(2):75-92.

14. Miller KL, Walt JG, Mink DR, et al. Minimal clinically important difference for the ocular surface disease index. Archives of ophthalmology (Chicago, III : 1960) 2010, 128(1):94-101.

15. Nilforoushan MR, Latkany RA, Speaker MG. Effect of artificial tears on visual acuity. Am J Ophthalmol 2005, 140(5):830-835.

16. Simmons PA, Vehige JG. Clinical performance of a mid-viscosity artificial tear for dry eye treatment. Cornea 2007, 26(3):294-302. 
17. Kobashi H, Kamiya K, Igarashi A, et al. Intraocular Scattering after Instillation of Diquafosol Ophthalmic Solution. Optom Vis Sci 2015, 92(9):e303-309.

18. Koh S, Maeda N, Ikeda C, et al. Effect of instillation of eyedrops for dry eye on optical quality. Invest Ophthalmol Vis Sci 2013, 54(7):4927-4933.

19. McGinnigle S, Eperjesi F, Naroo SA. A preliminary investigation into the effects of ocular lubricants on higher order aberrations in normal and dry eye subjects. Cont Lens Anterior Eye 2014, 37(2):106-110.

20. Diaz-Valle D, Arriola-Villalobos P, Garcia-Vidal SE, et al. Effect of lubricating eyedrops on ocular light scattering as a measure of vision quality in patients with dry eye. Journal of cataract and refractive surgery 2012, 38(7):1192-1197.

21. Montes-Mico R, Cervino A, Ferrer-Blasco T, et al. Optical quality after instillation of eyedrops in dryeye syndrome. Journal of cataract and refractive surgery 2010, 36(6):935-940.

22. Rieger G. Contrast sensitivity in patients with keratoconjunctivitis sicca before and after artificial tear application. Graefes Arch Clin Exp Ophthalmol. 1993;231(10):577-579.

23. Ishioka $\mathrm{M}$, Kato $\mathrm{N}$, Takano $\mathrm{Y}$, et al. The quantitative detection of blurring of vision after eyedrop instillation using a functional visual acuity system. Acta Ophthalmol. 2009;87(5):574-575.

24. Tung $\mathrm{Cl}$, Kottaiyan $\mathrm{R}$, Koh $\mathrm{S}$, et al. Noninvasive, objective, multimodal tear dynamics evaluation of 5 over-the-counter tear drops in a randomized controlled trial. Cornea. 2012;31(2):108-114.

25. van den Berg TJ. To the editor: Intra- and intersession repeatability of a double-pass instrument. Optom Vis Sci. 2010;87(11):920-921.

26. Lee K, Sohn J, Choi JG, Chung SK. Optical quality in central serous chorioretinopathy. Invest Ophthalmol Vis Sci. 2014;55(12):8598-8603.

27. Lee K, Sohn J, Choi JG, Chung SK. Optical quality in central serous chorioretinopathy. Invest Ophthalmol Vis Sci. 2014;55(12):8598-8603.

28. Cho JH, Bae SH, Kim HK, Shin YJ. Optical Quality Assessment in Patients with Macular Diseases Using Optical Quality Analysis System. J Clin Med. 2019;8(6):892.

29. Koh S, Tung Cl, Inoue Y, Jhanji V. Effects of tear film dynamics on quality of vision. Br J Ophthalmol. 2018;102(12):1615-1620.

30. Sullivan BD, Whitmer D, Nichols KK, Tomlinson A, Foulks GN, Geerling G, Pepose JS, Kosheleff V, Porreco A, Lemp MA: An objective approach to dry eye disease severity. Invest Ophthalmol Vis Sci 2010, 51(12):6125-6130.

31. Bitton E, Perugino C, Charette S: Comparison of Ocular Lubricant Osmolalities. Optom Vis Sci 2017, 94(6):694-699.

32. Goldman JN, Kuwabara T. Histopathology of corneal edema. Int Ophthalmol Clin 1968, 8(3):561-579.

\section{Tables}

Table 1. Demographic information and baseline results of ocular surface tests. 


\begin{tabular}{|c|c|c|c|c|c|c|c|}
\hline & \multirow{2}{*}{$\begin{array}{l}\text { Control } \\
\text { (31 eyes) }\end{array}$} & \multirow{2}{*}{$\begin{array}{l}\text { Mild ADDE } \\
\text { (28 eyes) }\end{array}$} & \multirow{2}{*}{$\begin{array}{c}\text { Severe } \\
\text { ADDE } \\
\text { (31 eyes) }\end{array}$} & \multirow{2}{*}{$\begin{array}{l}P \text { value } \\
\text { within } \\
\text { groups }\end{array}$} & \multicolumn{3}{|c|}{$P$ value (subgroup comparison) } \\
\hline & & & & & $\begin{array}{l}\text { control vs } \\
\text { mild }\end{array}$ & $\begin{array}{c}\text { control vs } \\
\text { severe }\end{array}$ & $\begin{array}{l}\text { mild vs } \\
\text { severe }\end{array}$ \\
\hline Male & 10 & 13 & 10 & 0.342 & 0.269 & 0.785 & 0.171 \\
\hline Female & 21 & 15 & 21 & & & & \\
\hline Age, $y$ & $38.13 \pm 13.79$ & $37.71 \pm 13.43$ & $36.35 \pm 14.40$ & 0.847 & 0.982 & 0.678 & 0.564 \\
\hline OSDI, units & $8.67 \pm 3.29$ & $24.04 \pm 5.22$ & $52.66 \pm 14.10$ & $<0.001$ & $<0.001$ & $<0.001$ & $<0.001$ \\
\hline TBUT, s & $11.84 \pm 3.12$ & $4.05 \pm 1.09$ & $3.17 \pm 0.99$ & 0.002 & $<0.001$ & $<0.001$ & 0.024 \\
\hline $\begin{array}{c}\text { Schirmer I, } \\
\text { mm }\end{array}$ & $16.26 \pm 4.98$ & $8.48 \pm 2.74$ & $3.83 \pm 1.25$ & $<0.001$ & $<0.001$ & $<0.001$ & $<0.001$ \\
\hline LLT, nm & $70.81 \pm 19.33$ & $59.29 \pm 15.33$ & $54.14 \pm 16.84$ & 0.015 & 0.009 & $<0.001$ & 0.452 \\
\hline
\end{tabular}

Note: Data were expressed as the means \pm SD. Due to multiple comparisons, the inspection level was corrected to 0.0125 .

Table 2. Optical quality comparison of participants before after artificial tears application

\begin{tabular}{|c|c|c|c|c|c|c|c|}
\hline & \multirow[t]{2}{*}{$\mathrm{n}$} & \multicolumn{3}{|c|}{ Mean OSI } & \multicolumn{3}{|c|}{ SD OSI } \\
\hline & & Baseline & $5 \min$ & $30 \mathrm{~min}$ & Baseline & $5 \min$ & $30 \mathrm{~min}$ \\
\hline Normal control & 31 & $0.54 \pm 0.23$ & $0.69 \pm 0.27$ & $0.56 \pm 0.29$ & $0.12 \pm 0.06$ & $0.20 \pm 0.10$ & $0.13 \pm 0.05$ \\
\hline t value & & & -2.418 & -0.338 & & -3.802 & -0.481 \\
\hline$P$ value & & & 0.019 & 0.737 & & 0.000 & 0.632 \\
\hline Mild ADDE & 28 & $0.83 \pm 0.38$ & $1.00 \pm 0.48$ & $0.91 \pm 0.53$ & $0.40 \pm 0.70$ & $0.13 \pm 0.05$ & $0.28 \pm 0.27$ \\
\hline t value & & & -1.444 & -0.597 & & 1.966 & 0.848 \\
\hline$P$ value & & & 0.155 & 0.553 & & 0.066 & 0.402 \\
\hline Severe ADDE & 31 & $1.05 \pm 0.65$ & $0.78 \pm 0.36$ & $0.83 \pm 0.76$ & $0.47 \pm 0.72$ & $0.15 \pm 0.08$ & $0.36 \pm 0.38$ \\
\hline t value & & & 2.073 & 1.214 & & 2.508 & 0.752 \\
\hline$P$ value & & & 0.044 & 0.299 & & 0.018 & 0.455 \\
\hline
\end{tabular}

Note: Data were expressed as the means \pm SD. "Mean OSI" and "SD OSI" refer to the mean value and standard deviation of the 20 -second OSI. 
Table 3. Statistical results of correlations between ADDE clinical tests and optical quality change

\begin{tabular}{lcccc}
\hline & OSDI & BUT & Schirmer I test & LLT \\
\hline MTF cut-off & & & & \\
$\mathrm{R}$ & 0.089 & 0.164 & -0.026 & -0.114 \\
$P$ & 0.505 & 0.216 & 0.843 & 0.399 \\
Mean OSI & & & & \\
$\mathrm{R}$ & -0.013 & -0.329 & -0.257 & -0.063 \\
$P$ & 0.921 & 0.011 & 0.050 & 0.643 \\
SD-OSI & & & & \\
$\mathrm{r}$ & 0.056 & -0.330 & -0.349 & -0.134 \\
$P$ & 0.676 & 0.011 & 0.007 & 0.320 \\
OSI $_{5 \min }$ & & & & \\
$\mathrm{r}$ & 0.063 & 0.261 & 0.457 & 0.042 \\
$P$ & 0.633 & 0.045 & 0.000 & 0.758 \\
OSI $_{30 \text { min }}$ & & & & \\
$\mathrm{r}$ & -0.093 & -0.013 & -0.037 & 0.178 \\
$P$ & 0.558 & 0.906 & 0.745 & 0.111 \\
\hline
\end{tabular}

Note: The MTF cut-off, mean OSI, and SD OSI values were measured at baseline. The OSI ${ }_{5 \min }$ and $\mathrm{OSI}_{30 \text { min }}$ were defined as the difference between the mean OSI at baseline and 5 or 30 minutes after AT instillation.

Figures
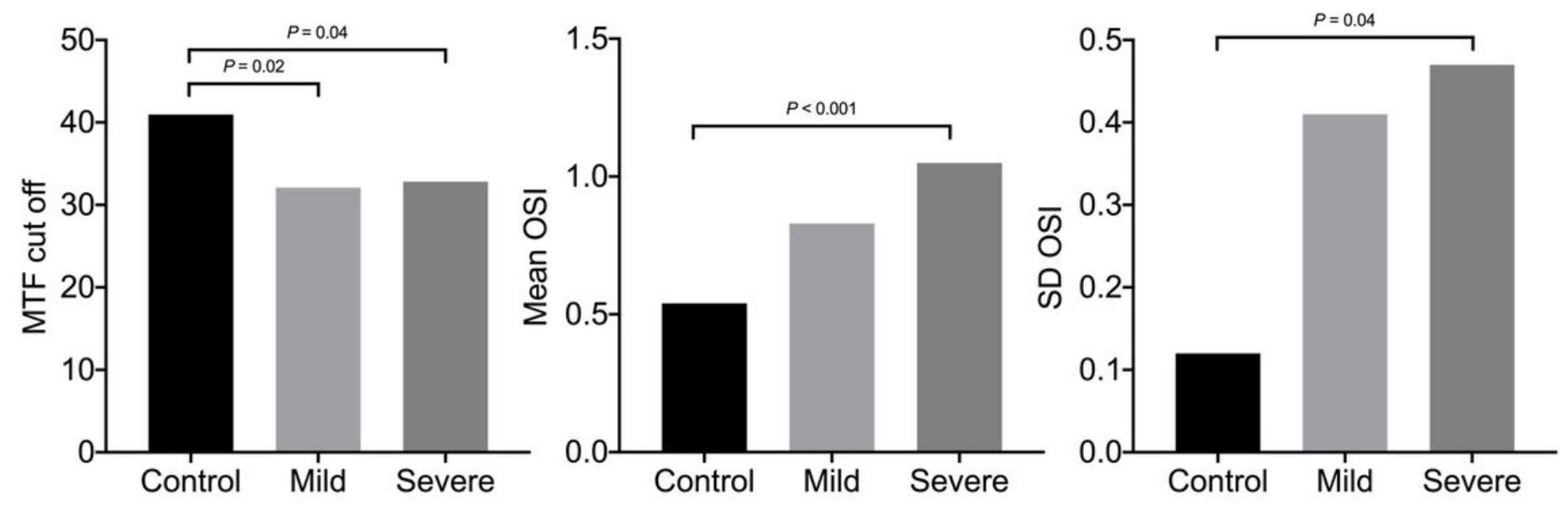

Figure 1

Baseline analysis of optical quality within ADDE patients and control subjects 